\title{
DENTRO DE UN ORDEN: IMAGINERIA TEATRAL
}

\author{
Benjamín Oltra \\ (Universitat Autònoma de Barcelona)
}

El libro con cuyo comentario pretendo usurpar algo del precioso tiempo del lector es, dentro de la obra de Erving Goffman, un elemento epistemológicamente sillar de su singular «invento» que bien podemos, fieles a sus gustos semánticos, calificar ya de entrada como «imaginería teatral»; trátase de Frame Analysis," un grueso tomo de casi seiscientas páginas, en cuarto, hasta la fecha no vertido al castellano, y que compendia toda la «magia» de la problemática y estilo «científicos» del sociólogo canadiense-norteamericano.

\section{Puntos de fuga}

Ya desde sus obtas más recientes, Goffman ha tenido la virtud de irnos clarificando los diversos sentidos que toma, en tornasolado juego de reflejos ideológicos, su discurso: ese exitoso artificio del «análisis dtamatúrgicos de la situación humana, producto característico de la ciencia social norteamericana de los años sesenta y setenta; versión del orden social desde la reducida - mas no poco complicada e importante- escala de la superficie de nuestra cotidianeidad; de la organización de la experiencia adquirida por los individuos, que Goffman suele identificar con un intertogante de puto sentido común (y que recojo en su lengua original, el inglés): What is it

1. Erving Goffman, Frame Analysis. An Essay on the Organization of Experience (Nueva York: Harper and Row, 1974). 
that's going on bere? Retengamos, para otientarnos, algunos pasajes significativos de sus obras. En 1967 venía así a calificar la «apariencia» de nuestra vida cotidiana:

«Los gestos que solemos calificar como vacíos son, tal vez, las cosas más plenas de todas.» ${ }^{2}$

Sigamos con una segunda cita que siempre me pareció algo inquietante:

«La vida social es una cosa ordenada, no engorrosa [...] ella contribuye para salvar la cara, sabiendo to mucho que hay que ganar no arriesgando nada.. ${ }^{3}$

La clave explicativa de esta aseveración la daría siete años más tarde, en este tercer párrafo, procedente ya del libro que ocupa nuestra atención:

«El marco [frame] organiza algo más que el significado; ordena también la integración [...] inmersos en él, sus partícipes no sólo percibirán el sentido de lo que acontece, sino que [...] acabarán espontáneamente integrados.» ${ }^{4}$

$\mathrm{El}$ «marco de la experiencia» sería, así, haz estructurante y envés significa* tivo de nuestra más elemental comunicación; la matriz del orden social, conformador de la experiencia individual, que para Goffman justifica nada menos que todo un modelo de análisis etiquetado como frame analysis. El profesor de Pennsylvania intenta aquí la quintaesencia de su visión, entreverada de fenomenología e interaccionismo simbólico, acerca de lo social concebido como código de reglas del juego cotidianas con un cierto poder significante; como malia cultural que envuelve (integra) nuestras vidas; como tnatco, en fin, «socialmente natural» de esta representación teatral en que queda transformada la vida social.

Mas hagamos un alto reflexivo. A la luz de este libro axial dentro de su obra, ¿con qué y cómo trabaja Goffman?; y ¿cuál es el sentido de su aportación? Los textos que he espigado anteriormente nos sirven, cada uno a su modo, de puntos de fuga para dibujar algunas de las originales pers.

2. Erving Goffman, Interaction Ritudl (Nueva York: Doubleday, 1967).

3. Ibidem.

4. Goffman, Frame Analysis..., op. cit., p. 345.

5. Un artículo de principios de los sesenta iniciaba en Estados Unidos este enfoque; vid. Sheldon Messinguer, Harold Samson y Robert D. Towne, "Life as Thea. ther: Some Notes on the Dramaturgic Approach", Sociometry, vol. 25 (1962). 
pectivas del profesor norteamericano. Comencennos por la materia que moldea en su trabajo. Goffman es un agudo observador del fluir cotidiano, en la mejor tradición reflexiva de los James, Schutz y Mead, y yo diría que incluso de Simmel. $\mathrm{L}$ a realidad que él ve (mediante su cognitive style) es naturalmente una fenomenología; un conjunto de eventos construidos con materiales inmediatos muy versátiles, pletóricos de significados. Tomando prestado un instante $\mathrm{i}$ lenguaje cartesiano, diríase que el conspicuo psicosociólogo ha condensado toda una nebulosa de res extensa a partir de un pe. netrante y concentrado estilo de res cogitans. Hasta aquí nada hay de mistetioso; pues es sabido que la Ciencia, en general, y las Ciencias Humanas, en particular, trabajan así, «desrealizando» to fenoménico para conceptuarlo, analizarlo e interpretario reintegrándolo, de esta suerte, de nuevo en el mundo. Lo singular de Goffman está, pienso yo, en el tipo de «materia social» recreada y, naturalmente, en la que deja fuera. En Goffman, el más «inocente» acontecer transfórmase en misterioso y poderoso juego de estrategias por la supervivencia. Por eso nos advertáa, un tanto solemnemente, que los «gestos» (que parecen) más vacíos son los más plenos; así, los intercambios más comunes, las relaciones más triviales, el mecánico sentido de un saludo, una efímera mirada, un gesto, una acción, un leve susurro, un intercambio fugaz de palabras dentro de la región de lo cotidiano, esconden sutiles, intrincados y poderosos juegos de poder, técnicas estratégicas y tácticas para el dominio y la supervivencia; en suma, todo un orden. He aquí el gran tema, presentado astutamente (1a «astucia de la tazón» que no ceja): el orden pequeño, natutal, el agua en que está inmerso el pez, que nunca se planteará; el orden que no lo parece, el cual es la forma más auténtica de orden. Mas aún podríamos seguir afinando el discurso; orden, ¿cuál?, ¿para qué?, ¿para quién? Curiosamente, e incluso irónicamente, aun siendo ei de este científico social un modelo vocado a mirar y revolver en el mundo de «lo dado por supuesto» (the taken for granted world), aquí, empero, se dan por supuesto muchas cosas. El orden es todo el orden, un mundo dado de valores y significaciones en sí mismo y para todos. El joven Marx tronaría de irritación ante tan exaspetante naturalismo. Y, sin embargo, posee su lógica; como es sólito una lógica a la que la ideología no está ausente. Acaso la obra de Goffman, sobre todo en el punto de inflexión de Frame Analysis, es la hábil proyección de un minucioso proceso introspectivo, de gran tiqueza potencial, sobre todo un sector de la vida social que acaba cerrándose como una esclusa y es incapaz de remontarse a otras dimensiones; pero que posee gran capacidad expresiva sobre lo captado. Quizás esa teflexión sobre el orden, más «aporía» que heurística, sea un intento de comprender las claves de la identidad social o comunitaria en la inmediatez significativa de nuestras relaciones diarias. En este sentido, el 
orden significativo de lo cotidiano, materia genuina sobre la que opera Goffman, aparecería como el orden natural de nuestra identidad, hasta el punto de que sí el drama goffmaniano tiene un objetivo más allá de su propia complaciente autorreflexión, éste sería el de hacer ver que la prin. cipal empresa de la sociedad consiste en la construcción de nuestra propia identidad, ${ }^{6}$ acaso la forma más elemental subjetiva de orden. Primera pers. pectiva, pues: el ritual aparente de la interacción humana con el trasfondo de la identidad es el más poderoso y profundo fundamento del orden.

\section{Hermetismos}

La vida social es una "cosa ordenada» de alto valor práctico, viene a decir el bueno de Goffman; tanto que el orden es providencial, inteligente, el cual ciertamente nos «envuelve» (Goffman goza convirtiéndonos en un show de personajes más o menos dignificados; para él el «yo», ese «self» de Mead, o "persona», es poco más que una ilusión óptica que emana del actor social); nos sumerge, sí, pero a cambio contribuye a que «salvemos la cara», socializándonos en la aventura de la integración, susurrándonos que en la "gran ruleta de la vida» la jugada exitosa, la ganancia, está precisamente en no arriesgar nada. Este discurso le deja a uno estupefacto. Brunner, en un cuidado trabajo, ${ }^{7}$ ensaya la óptica hermenéutica para establecer el múltiple sentido semiótico, simbólico e ideológico de esta proposición; su lectura va indagando la «tornasolada» naturaleza de los asertos goffmanianos; cestamos ante el experto retratista de un plano de la vida de la clase media norteamericana en problemática fase de redefinición de su identidad?; ¿acaso ttátase de la más sutil de las ideologías inmovilistas?; ¿es Goffman una suerte de version americana de astuto Machiavelli?; co acaso su obra no es más que un moderno breviario del oportunista ilustrado? El múltiple sentido de su discurso es innegable; baste con comparar el clima y estilo de sus libros tempranos como The Presentation of Self in Everyday Life (1959) o Asylums (1961) con Interaction Ritual (1967), Relations in Public (1971) o Frame Analysis (1974); la misma materia; renovadas variantes; consolidación de personales intereses; una misma óptica y... todo el arrollador y crítico escenario histórico norteamericano como trasfondo inteligentemente (herméticamente) presente en su obra. Brunner sugiere que la de Goffman es una de las más sofisticadas ideologías del orden dentro

6. Cf. algunas sugerencias de Philip Rosenberg en su recensión sobre Frame Analysis en The New York Times Book Review el 16 de febrero de 1975.

7. José Joaquín Brunner, "Hermenéutica del Orden" (Santiago de Chile: Documentos de trabajo de FLACSO, 1977). Mimeo. 
de las Ciencias Sociales académicas del siglo xx. ¿Qué tienen la Academia cientificosocial europea y norteamericana que siempre regresan, por una u otra vía, al vetusto problema hobbesiano del orden, sugitiendo de mil maneras más su conservación o justificación que su profunda comprensión? No entraremos por ahora en los vericuetos de tan azorante problemática.

\section{Novus ordo}

Decía Ortega, en una de sus piezas literarias, que el arte vivía «alojadon en su marco. ${ }^{8} \mathrm{Y}$ con su poderosa eurítmica escritura proseguia que el marco no era el ropaje del cuadro, pues el topaje sólo cubre; tampoco el ornato del lienzo, algo, a la postre, subsidiario; el marco, arguye Ortega, es un radical aislador que interrumpe el espacio real (la pared sobre la que cuelga) y toma zuestra mirada y nuestro goce introduciéndolos irresistible. mente en el territorio irreal del arte (la tela). Pues bien, este juego analógico de ese elegante meditador que era Ortega puede servir para adentratnos en el no menos analógico y metafórico juego de Goffman. También para Goffman el marco (frame) es una suerte de círculo aislante que contornea, organizándola, ruestra experiencia; mas a diferencia de la analogía orteguiana, en Goffman la «realidad» está dentro del marco y no fuera. Así, pues, el matco como definición de la tealidad social experimentada - Goffman dixit- cobra un papel decisivo: es la realidad y es la mirada del investigador. Dice Goffman que toda

«defnición de una situación se cimenta en principios de organización que gobiernan los acontecimientos $[\ldots]$ así como nuestra implicación subjetiva en ellos»."

Éste es el marco; un sistema de interacciones que organiza el juego de nuestra experiencia y su significado y, por tanto, da sentido a la persona - «yo» (self) del actor. El análisis del marco (frame analysis) sería, en consecuencia, el modelo que permite «vislumbrar» esa estructura individual/social de la experiencia. Con cierta socarrona modestia, Goff́man lo define como un slogan

«que refiere el examen en esos términos de organización de la experiencias. ${ }^{10}$

8. José Ortega y Gasset, «Meditación del Marco» (192I), en El Espectador (Antologia) (Madrid: Alianza, 1980); edición de Paulino Garagotri.

9. Goffman, Frame Analyse..., op. cit., p. 11.

10. Ibidem..., p. 12. 
Sin duda sólo una perspectiva de la múltiple interpretación del juego polisémico y poliideológico de las sucesivas astucias teatrales de Goffman, sólo una paciente hermenéutica permite captar por algún lado sti laberinto de observaciones. Si aplicamos al propio Goffman algunas de sus sugerencias observacionales y teóricas, tengo para mí que la operación resulta relativamente reveladora. El frame es, sí, su elemental concepción de la res extensa; también su modo y estilo de res cogitans; pero sobre todo es la cosmovisión en la que Goffman se siente confortable; en cierto irónico sentido es el «marco» del propio Goffman y lo que intelectualmente representa. En Goffman se hace diáfano que todo investigador, inmerso como está en la corriente de su objeto, acaba siendo atrapado por él; aunque no lo parezca. El marco es concebido como un escenario en el que los personajes (selves) cobran naturaleza de tales por estar precisamente «alojados» en él. Conviene estar siempre (integrado) en el escenario (orden); hay que estar «en escena» (onstage), pues de lo contrario el riesgo es set arrojado a las tinieblas de los «márgenes» (offstage) o quizás a las «bambalinas» (backstage); fuera de juego, en cualquier caso; algo así como ser expulsado de la tibia quietud del claustro materno.

Ahora bien, en la maqueta teórica proporcionada por nuestro autor acerca de la organización de la experiencia, no todo es armonía y quietud. En efecto, ese gran «escenario teatral» (theatrical frame) de la experiencia es el espacio social de nuestro acontecer (¿un eterno retorno, acaso?) compuesto de eventuales «marcos elementales» (primary frameworks) que nos sitúan en el sinfín de concretos eventos que tejen la experiencia y nos los etiquetan o «nombran». La pluralidad de «enmarques» en que nos movemos (la constelación de órdenes disciplinantes) tiene sus reglas, sus claves, que el juego de los actores problematiza constantemente (independientemente del cambio de las reglas y límites de todo el escenario - « \&rame limits»). Es una maravilla de lenguaje, mixtura de cromática artesanía y de ingeniería, el que Goffman maneja para etiquetar las turbaciones del orden, el conflicto; desde «frame brackets», o islotes dentro del marco, productores de tensión, hasta «frame ambiguities», ambigüedades y errores en el uso de las reglas del juego, y «frame disputes» o particiones dentro del juego que oponen versiones encontradas de la totalidad. Hasta una docena de situaciones humanas cotidianas pertenecientes al reino de la «conducta ordinaria» ciñe Goffman con la vitola del marco. 
Dentro de un orden: imaginería teatral

\section{Novísimo breviario de urbanidad}

En realidad, las pinturas goffmanianas no son otra cosa que una experta adaptación de las ideas de James. Goffram ha traducido en un discurso/lenguaje observacional y operativo -que edifica un estilo de investigar-- la máxima epistemológica de James: ¿En qué circunstancias pensamos que las cosas son reales? Su proceder consiste en it indagando la etiquetación de las cosas y su penetración en la mente individual, tejiendo así una tealidad flamada experiencia, que cobra realces diferentes según las circunstancias, según los «marcos». Las formas de organización de la experiencia que Goffman percibe tienen la función de hacer comprensible y significativa la conducta y su lenguaje en sus contextos apropiados. Cuando preguntamos, dirá Goffman, a alguien «¿cómo estás?» no inquirimos un informe sobre la salud del interrogado, sino que simplemente intentamos desplegar un contexto ( $($ marco») de amistad o, al menos, un clima de comunicación. Cuando llegamos a un lugar o ambiente diferente nos preguntamos (consciente o subconscientemente) « $\langle$ de qué va la cosa aquí?»); tratamos de hacernos con las claves forjando nuestro enmarque a partir de un contexto («marco») social, profesional, político... dado. La experiencia social es, en definitiva, una "constelación de órdenes», de acuerdo con este modelo. El orden es lo «adecuado» en cada momento («donde fueres haz lo que vieres», «buen porte $y$ buenos modales abren puertas principales», etcétera) de la relación y la presencia colectiva de los individuos. El orden, desde este punto de vista, preexiste a las personas $\mathrm{y}$, ex necessitate, es un haz de fuerzas integradoras en forma de un tejido de prescripciones y permisos. Difícil se hace entender el núcleo profundo de este discurso que parece jugar al escondite del lenguaje, encerrando palabtas dentro de palabras como si de una inacabable «matriochka» se tratase; que, por ejemplo, a la «desviación social» o «matginación» (un «des-orden») acaba calificándola de «impropiedad situacionał». Si no fuera algo exagerado diría que la preocupación de este discurso evoca, en ocasiones, el rancio aroma de los breviarios de urbanidad.

No dude el lector que el de Goffman es un modelo tan otiginal como sintomático de lo que podríamos llamar analógicamente el «tenebrismo» de las Ciencias Sociales, una permanente ambigüedad en los planos luminosos de la realidad presentada, en la que la oscuridad cumple su papel; una ambivalencia en el uso de la luz de la realidad y de la investigación; es, como era de esperar, un lenguaje propio del país de la abundancia (con sus crisis) y sus proverbiales regresos al «paraíso perdido» del liberalismo ensimismado. Mas, pienso yo, que sería una simpleza concluir que la mora* 
leja de Goffman es algo así como que nos dejemos de bromas y aprendamos a «salvar la cara»; esto es, la defensa cruda y cínica del otden en sus infinitos microótdenes cotidianos. Pero la verdad es que su «maqueta moral» no excede en mucho su algo episódico, ${ }^{11}$ notablemente reduccionista, modelo científico; e incluso me atrevería a decir que no tiene más secretos que los de su angosta imago mundi. Quizá lo inquietante es, como en la Gioconda de Leonardo $\rightarrow$ y la comparación favorece a Goffman- su hetmético tisueño semblante. ¿Es su «representación teatral» una comedia o una tragedia?, se preguntará, en definitiva, el lector. He aquí mi respuesta: el género, hoy por hoy, es francamente indefinido.

11. Una sugerencia sobte la consideración del modelo y la definición de la realidad de Goffman como «episódicos» puede verse en Gouldner, The Coming Crisis of Western Sociology (Nueva York: Avon, 1971). Vid. asimismo T. R. Young, «The Politics of Sociology: Gouldner, Goffman and Garfinkel», The American Sociologist, vol. 6 (noviembre de 1971). 